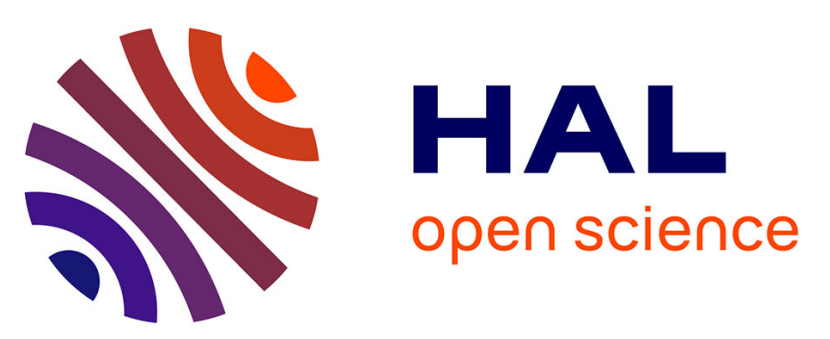

\title{
Identification of a predictive metabolic signature of response to immune checkpoint inhibitors in non-small cell lung cancer: METABO-ICI clinical study protocol
} Sarah Sannicolo, Matteo Giaj Levra, Audrey Le Gouellec, Caroline Aspord, Julien Boccard, Laurence Chaperot, Bertrand Toussaint, Denis Moro-Sibilot, Dalil Hannani, Anne-Claire Toffart

\section{To cite this version:}

Sarah Sannicolo, Matteo Giaj Levra, Audrey Le Gouellec, Caroline Aspord, Julien Boccard, et al.. Identification of a predictive metabolic signature of response to immune checkpoint inhibitors in nonsmall cell lung cancer: METABO-ICI clinical study protocol. Respiratory Medicine and Research, 2021, 80, pp.100845. 10.1016/j.resmer.2021.100845 . hal-03418402

\author{
HAL Id: hal-03418402 \\ https://hal.science/hal-03418402
}

Submitted on 7 Nov 2021

HAL is a multi-disciplinary open access archive for the deposit and dissemination of scientific research documents, whether they are published or not. The documents may come from teaching and research institutions in France or abroad, or from public or private research centers.
L'archive ouverte pluridisciplinaire HAL, est destinée au dépôt et à la diffusion de documents scientifiques de niveau recherche, publiés ou non, émanant des établissements d'enseignement et de recherche français ou étrangers, des laboratoires publics ou privés. 


\section{Identification of a predictive metabolic signature of response to}

\section{immune checkpoint inhibitors in non-small cell lung cancer:}

\section{METABO-ICI clinical study protocol}

Sarah SANNICOLO ${ }^{1,2}$, Matteo GIAJ LEVRA ${ }^{3,4}$, Audrey LE GOUELLEC ${ }^{1}$, Caroline ASPORD ${ }^{4,5}$, Julien BOCCARD ${ }^{6,7}$, Laurence CHAPEROT ${ }^{4,5}$, Bertrand TOUSSAINT ${ }^{1}$, Denis MORO-SIBILOT MT $^{3,4} 8$ Dalil HANNANI ${ }^{1 *}$, Anne-Claire TOFFART $T^{3,4,8 * \S}$

${ }^{1}$ Univ. Grenoble Alpes, CNRS, Grenoble INP, CHU Grenoble Alpes, TIMC-IMAG, Grenoble, France.

${ }^{2}$ Pôle Cancer et Maladies du sang, Centre Hospitalier Universitaire Grenoble Alpes, France

${ }^{3}$ Service Hospitalier Universitaire Pneumologie Physiologie, Unité d’Oncologie Thoracique, Pôle Thorax et Vaisseaux, Centre Hospitalier Universitaire Grenoble Alpes, France

${ }^{4}$ Institute for Advanced Biosciences, Immunobiology and Immunotherapy in Chronic Diseases, Inserm U 1209, CNRS UMR 5309, Université Grenoble Alpes, 38000 GrenobleFRANCE

${ }^{5}$ Etablissement Français du Sang Auvergne-Rhône-Alpes, R\&D Laboratory, 38000 Grenoble France

${ }^{6}$ School of Pharmaceutical Sciences, University of Geneva, Switzerland

${ }^{7}$ Institute of Pharmaceutical Sciences of Western Switzerland, University of Geneva, Switzerland

${ }^{8}$ Université Grenoble Alpes

* Co-senior authorship

${ }^{\S}$ Corresponding author: 
Anne-Claire TOFFART, atoffart@chu-grenoble.fr 


\section{ABSTRACT}

Background: Immune checkpoints inhibitors (ICI) are becoming new standards of care for the treatment of non-small cell lung cancer (NSCLC), both as first (alone or in association with chemotherapy) and second line. However, no powerful predictive biomarker of therapeutic response to $\mathrm{ICl}$ has been found to date. It has been recently shown that microbiota composition could influence the ability of patients to respond to $\mathrm{ICl}$. Indeed, the microbiota produces circulating metabolites that will subsequently act on immune system, the investigators hypothesized that plasma metabolic signature, reflecting a global microbiota function, could represent a predictive biomarker of response to $\mathrm{ICl}$.

Methods: Monocentric prospective study. Primary objective is to identify baseline metabolic signature (metabolomics analysis by Mass spectrometry) associated to $\mathrm{ICl}$ response. Secondary objectives are to link metabolic signature with microbiota composition (metagenomics analysis RNA 16S) and immune profile, and altogether with clinic response to $\mathrm{ICl}$. The study will include 60 NSCLC patients treated by ICI in $1^{\text {st }}, 2^{\text {nd }}$ or $3^{\text {rd }}$ line of treatment at the Grenoble Alpes University hospital (CHUGA) in 18 months. Patients that have received antibiotic or steroid treatment, 2 or 4 weeks before ICl initiation, respectively, will be excluded. Blood and feces will be collected prior to, at 2 months after $\mathrm{ICl}$ treatment initiation, and at 6 months or at progression.

Expected results: We expect to highlight a metabolic profile predictive of response to ICl. By identifying factors associated with early progression, we could avoid to treat potential nonresponding patients. Moreover, by restoring a favorable microbiota, patients' ability to respond to these treatments might be restored.

KEYWORDS: Non-small cell lung cancer, immunotherapy, metabolism, microbiota 


\section{ABBREVIATIONS}

CBC : Complete Blooding Count

EMA : European Medicines Agency

ICI: Immune Checkpoint Inhibitor

MDSC: Myeloid-Derived Suppressor Cells

NSCLC: Non-Small Cell Lung Cancer

RCC: Renal Cell Carcinoma 


\section{INTRODUCTION}

Immune checkpoint inhibitors (ICI) revolutionized the cancer therapeutic arsenal since the first approval for ipilimumab in 2011 (1) for metastatic melanoma. Nowadays, ICI are approved in many metastatic cancers, notably melanoma, non-small cell lung cancer (NSCLC), clear cell renal carcinoma (RCC), and head and neck cancer. A major limitation of these treatments is the relative low response rate and potential severe side-effects, combined with high costs. For instance, only a subset of NSCLC patients (around 20\%) exhibited an objective response and a long-term benefit when used in $2^{\text {nd }}$ line (2-4). One the other hand, $\mathrm{ICl}$ synergize with chemotherapy in $1^{\text {st }}$ line setting, improving objective response rate $(45.3 \%$ to $64.0 \%(5,6))$.

The discovery of a predictive biomarker of response to $\mathrm{ICl}$ represents a real challenge that will allow the selection of patients likely to respond. The latter is crucial to determine which patients will not benefit from ICI therapy, to minimize toxicity, prevent side effects and reduce treatment costs. Numerous studies already attempted to identify potential biomarkers. Notably, Myeloïd-Derived Suppressor Cell (MDSC) (7), eosinophil (8) and soluble CD25 (9) rates, or tumor infiltrating lymphocytes phenotype or function (10) for ipilimumab, and the expression of Programmed Death (PD)-1/PD Ligand (PDL)-1 within the tumor bed (11) and the tumor mutational burden (12), in response to anti-PD-1/PDL-1. Unfortunately, taken individually, these markers lack robust sensitivity and specificity.

Recently, gut microbiota composition appeared as an important factor influencing $\mathrm{ICl}$ responses in melanoma $(13,14)$ or in $\mathrm{RCC}$ and $\operatorname{NSCLC}(15)$.

Gut microbiota is now well recognized as a critical player in (cancer) immunity modulation throughout life. Indeed, gut microbiota triggers balanced pro- and antiinflammatory signaling with local and systemic immunomodulatory action. Microbiota can 
promote immune modulation through Toll-like Receptors (TLR) recognition of MicrobesAssociated Molecular Patterns (MAMPs), and the production of metabolites endowed with immunomodulatory functions (16). Several bacteria families/species have been associated with chemotherapy and $\mathrm{ICl}$ responses $(13-15,17)$ and with $\mathrm{ICl}$-associated toxicities (18). These studies clearly highlight the critical role of microbiota in cancer immunotherapy but the identified bacteria are diverse and study- and cohort-dependent, thus limiting the use of these microbiota signatures to anticipate $\mathrm{ICl}$ responses.

The diversity of identified bacteria strongly suggests that beyond species, the microbiota function (i.e. metabolic activity) might be a critical parameter. Indeed, it is now well recognized that some metabolites can directly influence immune polarizations, and that the metabolism of immune cells (immuno-metabolism) is critical for driving their functions. We thus strongly believe that microbiota-derived metabolic signature might strongly reflect its activity, beyond species identification, and could represent a "universal" biomarker for identifying responding and non -responding patients. Importantly, it has been recently shown that microbiota-derived Short-Chain Fatty Acids (SCFAs) metabolite production was associated with resistance to ipilimumab (19), highlighting the relevance of such strategy.

We present here our clinical study strategy, aiming to identify a plasma metabolic signature predictive of $\mathrm{ICl}$ response in NSCLC. High Performance Liquid ChromatographyMass Spectrometry (HPLC-MS/MS) untargeted metabolomics analysis will be performed. Gut microbiota signature and several immune parameters will also be determined in order to link these parameters with patients' metabolic profiles using chemometrics and bioinformatics. 


\section{CLINICAL STUDY PROTOCOL}

It is a prospective, observational, and monocentric study conducted at the Grenoble Alpes University Hospital. Protocol has been approved by Personal Protection Committee (07/02/2019). Patients must sign a consent form. Clinical trial ID is NCT04189679.

\subsection{Objectives}

The aim of this study is to characterize intestinal microbiota composition and function through plasma metabolic profile of NSCLC patients treated with $\mathrm{ICl}$, and to highlight a metabolic profile associated with response to immunotherapy.

Associations between the composition of the intestinal microbiota, the immune status and the response to $\mathrm{ICl}$ will be secondary objectives. The evolution of intestinal microbiota composition, metabolic signature, and immune status after $\mathrm{ICl}$ initiation will also be studied in order to identify dynamic correlations. Moreover, an eating habit questionnaire will be submitted to study the links between diet habits and microbiota function and composition.

\subsection{Study population}

All metastatic NSCLC patients, over 18 years old, and newly treated by $\mathrm{ICl}$ are included. Patients benefiting from an ICI re-challenge are excluded. Patients could be treated in first, second or third line, and in first line patients could be treated with $\mathrm{ICl}$ alone or in association with chemotherapy. Patient with at least one measurable lesion as defined by RECIST are eligible. Patients who have received antibiotic within 2 weeks before the initiation of $\mathrm{ICl}$ or corticosteroids (>20mg of prednisolone or equivalent per day) within 4 weeks are excluded. 


\subsection{Data collection}

At baseline, demographic data (sex, date of birth, height, weight, weight loss, performance status), cancer characteristics (histological type, date of diagnosis, stage at diagnosis, anti-tumor treatment received before, number and localization of metastasis are collected. Patients will also have to complete a questionnaire about their eating habits at initiation of $\mathrm{ICl}$. Throughout the study, we will record treatment characteristics (name of molecule, frequency and dose administered and antibiotics, probiotics, anti-gastric acids or corticosteroids administered within the 2 months prior to inclusion and all along the treatment), response to $\mathrm{ICI}$ (RECIST 1.1 criteria) and vital status. A central radiological examination blinded to clinical or biological features will be performed.

Results of biological analyses, usually performed at baseline thus before $\mathrm{ICl}$ administration, will also be collected: Complete Blood Count, blood electrolytes, creatinine, urea, SGOT and SGPT transaminases, alkaline phosphatases, $\gamma$-glutamyltransferase, bilirubin, lactate dehydrogenase and thyroid hormones.

\subsection{Sample collection}

Samples will be collected prior to immunotherapy initiation (Baseline M0), 2 and 6 months (M2 and M6) after, or at disease progression (Mx) (Figure 1, Table 1)

Blood sample will be collected and immediately processed to collect the plasma for metabolomics and immunological analyses. Plasma will be frozen at $-80^{\circ} \mathrm{C}$ before analysis.

Stools will be collected $24 \mathrm{~h}$ before immunotherapy initiation (M0), prior the following cures ( $\mathrm{M} 2$ and $\mathrm{M} 6$ or $\mathrm{Mx}$ ) and stored at $4^{\circ} \mathrm{C}$ at home by the patients. Samples will then be brought to the hospital, using ice pack in hermetic bags to ensure a $4^{\circ} \mathrm{C}$ temperature 
maintenance. Stools are then immediately stored at $-80^{\circ} \mathrm{C}$ prior DNA extraction and subsequent sequencing, or prior dilution in sterile water for metabolomics analysis on fecal water samples.

\subsection{Analyses of biological samples}

All biological analyses will be performed at the end of the study, at the same time, to avoid batch-related analysis biases. Plasma and fecal water metabolic profiles will be analyzed by untargeted HPLC-MS/MS metabolomics, while microbiota composition will be determined by 165 RNA sequencing. Circulating immune mediators will also be analyzed, by luminex technology to characterize cytokine profiles and detect relevant soluble immune receptors/ligands, including, IL-2, IL-6, IL-8, IL-10, IL-18, IFN- - , TNF $\alpha$, soluble receptor CD25 (IL-2R $\alpha$ ) and also a panel of co-stimulatory or inhibitory soluble immune checkpoints, namely soluble PD-1 BTLA, CD27, CD28, CD80/B7-1.

\subsection{Statistical plan}

\subsubsection{Number of patients to include}

We plan to include both $1^{\text {st }}$ line and $2^{\text {nd }} / 3^{\text {rd }}$ line patients. In first line, objective response rate (ORR) is about $40 \%$ among PD-L-1>50 $(20,21)$ and about $20 \%$ in second line (2-4). About $30 \%$ of patients have a tumor with PD-L1 expression $\geq 50 \%$. We therefore estimate that $1 / 3$ of patients will be included in the $1^{\text {st }}$ line and $2 / 3$ in the $2^{\text {nd }}$ or $3^{\text {rd }}$ line. As expected, the association of chemotherapy and pembrolizumab obtained EMA authorization at the beginning of the study. ORR were $48 \%$ in patients with non-squamous NSCLC (22) and $63 \%$ in squamous NSCLC (23). Depending on when this combination of treatments would be 
available, it is possible that $2 / 3$ of the patients will be treated in $1^{\text {st }}$ line. But it would not change the primary objective and the number of patients to include.

Our objective is to identify a plasma metabolic profile associated with the response to $\mathrm{ICl}$ with a sensitivity greater than $80 \%[95 \% \mathrm{Cl}, 67-93]$ and a specificity greater than $80 \%$ [95\% Cl, 67-93]. The inclusion of 60 patients (20 in $1^{\text {st }}$ line and 40 in $2^{\text {nd }}$ or $3^{\text {rd }}$ line) should allow us to achieve this objective.

The planned duration of inclusions is 18 months, with an objective of 60 patients included.

\subsubsection{Bioinformatics and multi-block chemometrics}

As designed, this clinical study will provide a high amount of data spread over several data blocks, namely the Metabolome, Metagenome, "Immunome" and "Clinicome" data blocks. The integration of this collection of data tables is challenging, and requires a multi-block modeling analysis. The purpose of multi-block modeling is to offer an overall picture of all the available data, to assess the relevance of each block and to investigate relationships of variables that may be linked between data (24). The corresponding models offer two levels of analysis: (i) at the individual block level, scores and loading vectors are specifically related to each data table; (ii) at the global scale, common information is derived from the combination of all data tables. A global overview of major trends is thus obtained in order to highlight common sources of variability, but also differences and block-specific information. Similar to standard single-block analysis, both unsupervised (descriptive) and supervised (predictive) approaches can be implemented (25). This type of approach offers suitable data analysis tools when the information available to characterize a set of observations is distributed over several matrices. Extensive statistical validation will be 
carried out using resampling procedures. Both cross-validation and permutation tests will be performed to ensure the predictive ability of the models, both in terms of sensitivity and specificity.

\subsubsection{Statistical analysis}

Patients' characteristics will be described in number and percentages for the qualitative variables and in median (interquartile range $25 \%-75 \%$ ) for the quantitative ones. Comparisons between metabolic profiles will be performed using the Wilcoxon test for quantitative variables and Chi square or Fisher exact tests for qualitative variables. Bonferroni correction will be applied for multiple comparisons when comparing variables across groups.

After identification of these profiles, a sensitivity analysis according to the variable "ICI alone or in combination with chemotherapy" will be performed.

All statistical analyses will be performed using SAS 9.4 (SAS Institute, Cary, NC, USA). 


\section{EXPECTED RESULTS}

The link between gut microbiota, host immunity and response to immunotherapy is well established, even if many aspects remain to be understood. Again, all the studies supporting such link also revealed a great diversity of microbes associated to treatment responses $(9,13-15,17,27,28)$. We believe that, beyond bacteria species, their metabolic activity deeply affects host immunity and thus might reflect both microbiota "quality" and subsequent host's immune status. We have designed this study for addressing these questions, attempting to link these parameters (Figure 2).

We expect to find a plasma metabolic signature (metabolome) strongly associated with patients' responses to immunotherapy (clinicome). Also, we expect to be able to link these plasma profiles with fecal metabolic activity and gut microbiota composition (metagenome). Altogether, these data will not only allow us identifying a predictive signature but should also provide a better understanding of the link between microbiota composition, function and impact on host systemic metabolic profile.

Since the ability to respond to cancer immunotherapy is directly dependent on the host's immune status, we will assess multiple immune parameters, and notably soluble pro- and anti-inflammatory factors (immunome). We will focus our analysis on soluble immune mediators because their dosage can be easily implemented in clinical routine diagnosis, if required.

The immunome data block will be correlated with all the other blocks in order to reveal the existing links between data sources.

Importantly, when we designed our study, we strongly believed that a multi-block analysis strategy could lead to a powerful predictive algorithm. A recent publication 
demonstrated that such integrative strategy allows the identification of critical metabolic pathways (29).

In order to gain further insights into these complexes and dynamic parameters, we also plan to analyze samples at 2 and 6 months post treatment initiation, to better understand the dynamic relationship between all the studied data blocks. This analysis might reveal the direct causality between each block, for instance the influence of the microbiota composition evolution on host metabolism and subsequent immunity (including the ability to respond to immunotherapy).

The perspectives of this work are multiple. First, this clinical study represents a multidisciplinary clinical proof-of-concept study that will pave the way for a multi-centric prospective clinical study that will fully validate our future findings. Also, one can imagine that patients identified as non-responders (based on metabolic signatures) could be preconditioned either by probiotics and/or prebiotics in order to optimize both gut microbiota composition and function prior to immunotherapy initiation and thus to maximize their chance to respond to immunotherapy. 


\section{Acknowledgements}

This work was supported by Roche Institute and Fondation du Souffle-Fonds de Recherche en Santé Repiratoire (FdS-FRSR)

D.H. is supported by GEFLUC Dauphiné-Savoie, Ligue contre le Cancer Comité Isère, Université Grenoble Alpes IDEX Initiatives de Recherche Stratégiques.

\section{Conflict of interest}

Sarah Sannicolo, Audrey Le Gouellec, Caroline Aspord, Julien Boccard, Laurence Chaperot. Bertrand Toussaint and Dalil Hannani declare no conflict of interest.

Matteo Giaj Levra declares conflicts of interest with Astra Zeneca, BMS, MSD, Roche; Denis Moro-Sibilot with BMS, MSD, Astra Zeneca, Roche and Anne Claire Toffart with Astra Zeneca, BMS, Boehringer Ingelheim, Novartis, MSD, Pfizer and Roche. 


\section{REFERENCES}

1. Robert C, Mateus C. Anticorps anti-CTLA-4 - Une avancée thérapeutique majeure dans le traitement du mélanome métastatique. Med Sci 2011;850-858. https://doi.org/10.1051/medsci/20112710013

2. Borghaei H, Paz-Ares L, Horn L, Spigel DR, Steins M, Ready NE, et al. Nivolumab versus Docetaxel in Advanced Nonsquamous Non-Small-Cell Lung Cancer. N Engl J Med. 2015;373(17):1627-39. DOI: 10.1056/NEJMoa1507643

3. Herbst RS, Baas P, Kim D-W, Felip E, Pérez-Gracia JL, Han J-Y, et al. Pembrolizumab versus docetaxel for previously treated, PD-L1-positive, advanced non-small-cell lung cancer (KEYNOTE-010): a randomised controlled trial. The Lancet. 2016;387(10027):1540-50. https://doi.org/10.1016/S0140-6736(15)01281-7

4. Brahmer J, Reckamp KL, Baas P, Crinò L, Eberhardt WEE, Poddubskaya E, et al. Nivolumab versus Docetaxel in Advanced Squamous-Cell Non-Small-Cell Lung Cancer. N Engl J Med. 2015;373(2):123-35. DOI: 10.1056/NEJMoa1504627

5. Gandhi L, Rodríguez-Abreu D, Gadgeel S, Esteban E, Felip E, De Angelis F, et al. Pembrolizumab plus Chemotherapy in Metastatic Non-Small-Cell Lung Cancer. N Engl J Med. 2018;378(22):2078-92. DOI: $\underline{10.1056 / N E J M o a 1801005}$

6. Paz-Ares L, Luft A, Vicente D, Tafreshi A, Gümüş $M$, Mazières J, et al. Pembrolizumab plus Chemotherapy for Squamous Non-Small-Cell Lung Cancer. N Engl J Med. 2018;379(21):2040-51. https://doi.org/10.1056/nejmoa1810865

7. Meyer C, Cagnon L, Costa-Nunes CM, Baumgaertner P, Montandon N, Leyvraz L, et al. Frequencies of circulating MDSC correlate with clinical outcome of melanoma patients treated with ipilimumab. Cancer Immunol Immunother. 2014;63(3):247 - 57. DOI: $\underline{10.1007 / \mathrm{s} 00262-013-1508-5}$ 
8. Ferrucci PF, Gandini S, Cocorocchio E, Pala L, Baldini F, Mosconi M, et al. Baseline relative eosinophil count as a predictive biomarker for ipilimumab treatment in advanced melanoma. Oncotarget 2017; 8(45):79809-79815. DOI: 10.18632/oncotarget.19748

9. Hannani D, Vétizou M, Enot D, Rusakiewicz S, Chaput N, Klatzmann D, et al. Anticancer immunotherapy by CTLA-4 blockade: obligatory contribution of IL-2 receptors and negative prognostic impact of soluble CD25. Cell Res. 2015;25(2):208-24. DOI: $\underline{10.1038 / c r .2015 .3}$

10. Lee N, Zakka LR, Mihm MC, Schatton T. Tumour-infiltrating lymphocytes in melanoma prognosis and cancer immunotherapy. Pathology. 2016;48(2):177-87. DOI: $\underline{10.1016 / j . p a t h o l .2015 .12 .006}$

11. Rizvi NA, Hellmann MD, Snyder A, Kvistborg P, Makarov V, Havel JJ, et al. Mutational landscape determines sensitivity to PD-1 blockade in non-small cell lung cancer. Science. 2015;348(6230):124-8. DOI:10.1126/science.aaa1348

12. Hendriks LE, Rouleau E, Besse B. Clinical utility of tumor mutational burden in patients with non-small cell lung cancer treated with immunotherapy. Transl Lung Cancer Res. 2018;7(5):647-60. DOI: $\underline{10.21037 / \text { tlcr.2018.09.22 }}$

13. Sivan A, Corrales L, Hubert N, Williams JB, Aquino-Michaels K, Earley ZM, et al. Commensal Bifidobacterium promotes antitumor immunity and facilitates anti-PD-L1 efficacy. Science. 2015;350(6264):1084-9. DOI: $10.1126 /$ science.aac4255

14. Gopalakrishnan V, Spencer CN, Nezi L, Reuben A, Andrews MC, Karpinets TV, et al. Gut microbiome modulates response to anti-PD-1 immunotherapy in melanoma patients. Science. 2018;359(6371):97-103. DOI: 10.1126/science.aan4236

15. Routy B, Le Chatelier E, Derosa L, Duong CPM, Alou MT, Daillère R, et al. Gut microbiome influences efficacy of PD-1-based immunotherapy against epithelial tumors. 
Science. 2018;359(6371):91-97. DOI: 10.1126/science.aan3706

16. Zitvogel L, Ma Y, Raoult D, Kroemer G, Gajewski TF. The microbiome in cancer immunotherapy: Diagnostic tools and therapeutic strategies. Science. 2018;359(6382):136670. DOI: $\underline{10.1126 / \text { science.aar6918 }}$

17. Vétizou $M$, Pitt JM, Daillère $R$, Lepage $P$, Waldschmitt $N$, Flament $C$, et al. Anticancer immunotherapy by CTLA-4 blockade relies on the gut microbiota. 2015 27;350(6264):107984. DOI: $\underline{10.1126 / \text { science.aad1329 }}$

18. Chaput N, Lepage P, Coutzac C, Soularue E, Le Roux K, Monot C, et al. Baseline gut microbiota predicts clinical response and colitis in metastatic melanoma patients treated with ipilimumab. Ann Oncol. 2017;28(6):1368-79. DOI: 10.1093/annonc/mdx108

19. Coutzac C, Jouniaux J-M, Paci A, Schmidt J, Mallardo D, Seck A, et al. Systemic short chain fatty acids limit antitumor effect of CTLA-4 blockade in hosts with cancer. Nat Commun. 2020;11(1):2168. DOI: 10.1038/s41467-020-16079-x

20. Mok TSK, Wu Y-L, Kudaba I, Kowalski DM, Cho BC, Turna HZ, et al. Pembrolizumab versus chemotherapy for previously untreated, PD-L1-expressing, locally advanced or metastatic non-small-cell lung cancer (KEYNOTE-042): a randomised, open-label, controlled, phase 3 trial. The Lancet. 2019;393(10183):1819-30. DOI: 10.1016/S0140-6736(18)32409-7

21. Reck $M$, Rodríguez-Abreu $D$, Robinson AG, Hui $R$, Csőszi $T$, Fülöp $A$, et al. Pembrolizumab versus Chemotherapy for PD-L1-Positive Non-Small-Cell Lung Cancer. N Engl J Med. 2016;375(19):1823-33. DOI: 10.1056/NEJMoa1606774

22. Gadgeel S, Rodríguez-Abreu D, Speranza G, Esteban E, Felip E, Dómine M, et al. Updated Analysis From KEYNOTE-189: Pembrolizumab or Placebo Plus Pemetrexed and Platinum for Previously Untreated Metastatic Nonsquamous Non-Small-Cell Lung Cancer. J Clin Oncol. 2020;38(14):1505-17. DOI: 10.1200/JCO.19.03136 
23. Paz-Ares L, Vicente $D$, Tafreshi A, Robinson A, Soto Parra $H$, Mazières J, et al. A Randomized, Placebo-Controlled Trial of Pembrolizumab Plus Chemotherapy in Patients With Metastatic Squamous NSCLC: Protocol-Specified Final Analysis of KEYNOTE-407. J Thorac Oncol.2020;15(10):1657-69. DOI: 10.1016/j.jtho.2020.06.015

24. Boccard J, Rudaz S. Harnessing the complexity of metabolomic data with chemometrics: Metabolomic data analysis with chemometrics. J Chemom. 014;28(1):1-9. https://doi.org/10.1002/cem.2567

25. Boccard J, Rutledge DN. A consensus orthogonal partial least squares discriminant analysis (OPLS-DA) strategy for multiblock Omics data fusion. Anal Chim Acta. 2013;769:309. DOI: $\underline{10.1016 / j . a c a .2013 .01 .022}$

26. Boccard J, Rudaz S. Exploring Omics data from designed experiments using analysis of variance multiblock Orthogonal Partial Least Squares. Anal Chim Acta. 2016;920:18-28. DOI:

\section{$\underline{10.1016 / \text { i.aca.2016.03.042 }}$}

27. Viaud S, Saccheri F, Mignot G, Yamazaki T, Daillere R, Hannani D, et al. The Intestinal Microbiota Modulates the Anticancer Immune Effects of Cyclophosphamide. Science. 2013;342(6161):971-6. DOI: 10.1126/science.1240537

28. Matson V, Fessler J, Bao R, Chongsuwat T, Zha Y, Alegre M-L, et al. The commensal microbiome is associated with anti-PD-1 efficacy in metastatic melanoma patients. Science. 2018;359(6371):104-8. DOI: 10.1126/science.aao3290

29. Metwaly A, Dunkel A, Waldschmitt N, Raj ACD, Lagkouvardos I, Corraliza AM, et al. Integrated microbiota and metabolite profiles link Crohn's disease to sulfur metabolism. Nat Commun. 2020;11(1):4322. DOI: 10.1038/s41467-020-17956-1 


\section{Figure legends}

Screening and selection visit

\begin{tabular}{|c|c|c|}
\hline \multicolumn{3}{|c|}{ Vo - Initial visit } \\
\hline Collection of stool sample & sit at 2 mor & \\
\hline Collection of stool sample & Blood sample & Treatment \\
\hline \multicolumn{3}{|c|}{ V2 - End of study visit at tumor progression or 6 months } \\
\hline Collection of stool sample & Blood sample & Treatment \\
\hline
\end{tabular}

Figure 1. Visits summary table and associated sampling and treatment.

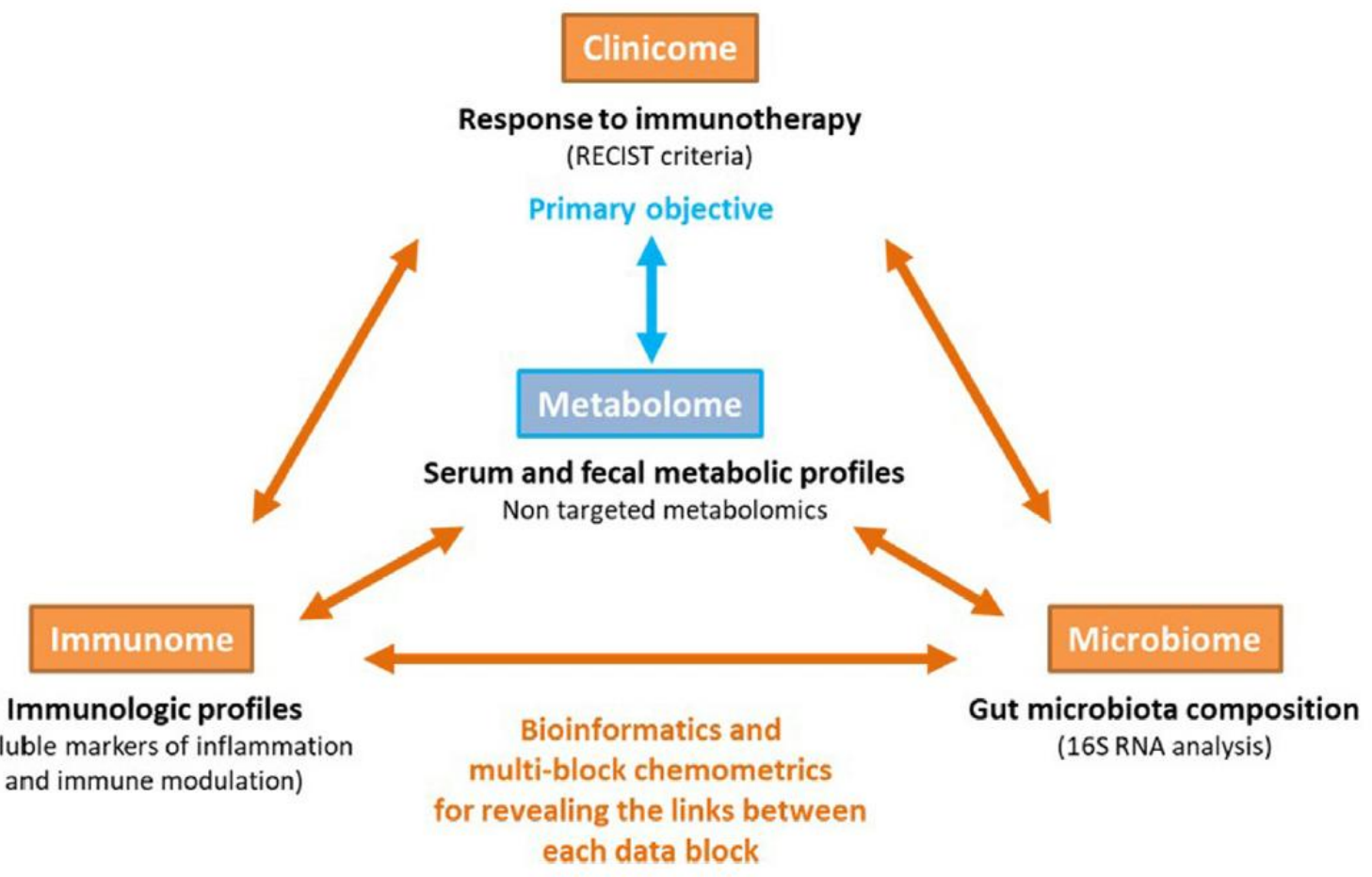


Figure 2: Study principle: Primary objective: to demonstrate a link between the metabolome and response to immunotherapy ("Clinicome"). Secondary objectives: to study the link between microbiota composition (microbiome), its metabolic activity (metabolome), host immunity (immunome) and treatment response (clinicome). 
Table 1. Investigations summary table for patient

\begin{tabular}{|l|l|l|l|l|}
\hline & Screening & V0 & V1 & V2 \\
\cline { 2 - 5 } & D-28 to D-1 & Start of & M2 & M6 or Tumor \\
\hline Informed consent & treatment & & & \\
\hline Demography & $\mathrm{X}$ & & & \\
\hline Previous treatment(s) & $\mathrm{X}$ & & & $\mathrm{X}$ \\
\hline Stool collected at home 24 & & & $\mathrm{X}$ & \\
\hline to 48 hours before visit & & & $\mathrm{X}$ & $\mathrm{X}$ \\
\hline Blood sample & & $\mathrm{X}$ & $\mathrm{X}$ & $\mathrm{X}$ \\
\hline Weight & & $\mathrm{X}$ & $\mathrm{X}$ & $\mathrm{X}$ (except in case \\
\hline ICl & & $\mathrm{X}$ & $\mathrm{X}$ & of progression) \\
\hline 1.1) & & & $\mathrm{X}$ & $\mathrm{X}$ \\
\hline Vital status & & & & \\
\hline
\end{tabular}

